\title{
Ethical Concerns in Poultry Production: A German Consumer Survey About Dual Purpose Chickens
}

\author{
Maria Busse $^{1}$ (D) Maria Lee Kernecker ${ }^{1}$ (D) Jana Zscheischler $^{1}$ (iD $\cdot{\text { Felix } \text { Zoll }^{1} \text { (D) }}^{\text {. }}$ \\ Rosemarie Siebert ${ }^{1}$
}

Accepted: 9 October 2019 / Published online: 18 October 2019

(c) The Author(s) 2019

\begin{abstract}
The paper offers insights into the acceptability of ethical issues in poultry production and how this situation provides an opportunity to transform the prevailing system into a more sustainable one. The survey among German consumers reveals that killing day-old chicks is a well-known practice and is rated as "very problematic". In contrast, dual-purpose chickens are mostly unknown but are considered a positive alternative to killing day-old chicks (after the concept has been explained). Consumer clusters were identified regarding purchasing criteria for dual-purpose chickens, purchasing routines and socio-economic factors. Three of the five clusters- the perfectionists, idealists, and realists-turned out to be potential buyers. To develop a suitable marketing strategy, it is recommended that the added value of dual-purpose chickens be comprehensibly communicated. From a multi-level perspective, rearing dual-purpose chickens has a competitive disadvantage compared to system-compliant alternatives (in-ovo sexing, "lay hen brothers"). Through increasing external pressure, the different alternatives can jointly contribute to a regime shift.
\end{abstract}

Keywords Acceptability · Consumer attitudes · Cluster analysis · Chicken husbandry $\cdot$ Killing of day-old chicks $\cdot$ Niche innovation

Maria Busse

maria.busse@zalf.de

Maria Lee Kernecker

maria.kernecker@zalf.de

Jana Zscheischler

jana.zscheischler@zalf.de

Felix Zoll

felix.zoll@zalf.de

Rosemarie Siebert

rsiebert@zalf.de

1 Leibniz Centre for Agricultural Landscape Research -ZALF, Eberswalder Str. 84,

15374 Müncheberg, Germany 


\section{Introduction}

The "conventional" agro-food system and intensive farming are currently the subject of controversy, discussion and criticism in European societies (Hatt et al. 2016). Reasons for this critique include that market-oriented differentiation, labour division, efficiency efforts, and price competition often lead to unintended ecological, social, and ethical side effects (Bruijnis et al. 2015; Morgan et al. 2006; Raynolds 2004). One example of such ethical side effects is the killing of male day-old chicks from specialized layer chicken varieties (Bruijnis et al. 2015). Male chicks of these varieties are "useless" because they put on meat slowly and in small quantities (Leenstra et al. 2010). In Germany, the number of killed chicks is estimated at 45 million per year (Hörning and Häder 2015). This practice is thus a production branch of considerable economic importance. A significant portion of society and numerous scientists in the field of animal ethics consider the death of chicks as an animal welfare issue, although this is not a self-evident fact (cf. Yeates 2010; Bruijnis et al. 2015). As such, it is not surprising that the issue of killing chicks has also gained media attention in recent years. Due to society's demand for ethical chick treatment, the agro-food sector (breeding companies, hatcheries, organic farming associations, and retailers) and science have been dedicated to seeking alternatives to killing chicks (Leenstra et al. 2010).

At the moment, the sector prefers solutions that remain largely in line with the prevailing agricultural regime and are compatible with its persisting structures and practices (cf. Geels 2002; Geels and Schot 2007). From a sustainability perspective, the poultry production structure is problematic because it is based on a few monopolistic breeding companies and performance hybrid animals. Such animals are limited in their species-specific and healthy development. In ovo sexing and fattening of "lay hen brothers" are seen as potential economically viable solutions because they build on conventional hybrid breeds and established market structures. In ovo sexing refers to determining the sex of fresh eggs to sort out male eggs (Krautwald-Junghanns et al. 2018; Galli et al. 2017; Kaleta and Redmann 2008). The fattening of "lay hen brothers" deals with rearing layer-variety male chicks of conventional hybrid breeds for meat (Krautwald-Junghanns et al. 2018; Bruijnis et al. 2015). Whereas in ovo sexing is still in its infancy, fattening male chicks is an increasingly disseminated agricultural practice. In contrast to these options, there are some innovative and regional alternatives (e.g., "ei care" in northeastern Germany, "Ei AG Zweinutzungshuhn" in Switzerland, sunbird farms in USA), which strive to reform the conventional agri-food system by relying on organic production of dual-purpose chickens instead of highperformance breeds. Dual-purpose chicken production uses both eggs and meat from the same-but less specialized-chicken variety from a time before breeding was divided into layer and meat varieties (Bruijnis et al. 2015). This type of production has lower profitability and competes with other forms of poultry husbandry. Furthermore, it is more expensive than keeping hybrid chickens because dual-purpose chickens lay fewer eggs and put on less meat more slowly 
than specialized chicken types (cf. Bruijnis et al. 2015). In the course of increasing attention to animal welfare and sustainability issues in poultry production, the breeding possibilities and profitability of dual-purpose chickens have recently been scientifically explored after decades of neglecting such potential (e.g., Hörning and Häder 2015; Damme 2015; Icken et al. 2013; Leenstra et al. 2010).

In addition to agronomical insights, knowledge about social acceptability (attitudes and behaviour of consumers) is needed to promote a welfare-oriented and sustainable transformation of the agri-food system. Only if consumers know and appreciate the additional value of innovations, such as dual-purpose chicken husbandry products, can they be successful on the market (e.g., Klerkx et al. 2010; Zander et al. 2013). Whereas a growing body of research has been conducted on the social acceptability of organic food in general (e.g., Hempel and Hamm 2016; Zander and Hamm 2010), research on acceptability regarding alternatives to killing day-old chicks is still in its infancy (e.g., Brümmer et al. 2018; Gremmen et al. 2018; Leenstra et al. 2011). There is a lack of studies that represent consumers' attitudes regarding dualpurpose chickens despite this issue's rise to prominence during the last few decades. Using an innovation perspective to understand complex systemic interactions (e.g., roles of different actors at various levels) and reveal systemic "lock-in effects" can complement insights gained by exploring the acceptability of innovations (cf. Hatt et al. 2016; Spaargaren 2011). Knowledge about agri-food system functioning and innovation processes combined with social acceptability insights can be used to evaluate market potentials and derive policy strategies for supporting the transition into a more sustainable and welfare-oriented agri-food system. While there are a few studies on alternatives to killing day-old chicks using an innovation system perspective (Diehl 2016; Bruijnis et al. 2015), studies that analyse both social acceptability and the innovation system are still needed in this field.

Our paper seeks to contribute to the abovementioned research gaps by providing results of a recent representative consumer survey. The survey is linked to a specific dual-purpose chicken initiative called "ei care" in northeastern Germany (www. aktion-ei-care.de). The overall objective in our paper is to analyse the acceptability of dual-purpose chicken products and their corresponding potential to change the current agri-food system. Considering acceptability as a complex and social concept (cf. Busse and Siebert 2018), we focus on the characterization of consumer groups (cluster analysis) to derive recommendations for suitable communication policy and marketing strategy for dual-purpose chicken production. To adequately address the abovementioned nested complexity of agro-environmental systems and their social contextualization, we additionally apply a multi-level perspective (MLP) (e.g., Geels 2002) in combination with a social practice theory (e.g., Reckwitz 2002).

The study aims at responding to the following research questions:

1. How do consumers assess the "killing of day-old chicks" and dual-purpose chickens?

2. How well informed do consumers feel about these topics?

3. Which conditions are important for consumers to potentially buy dual-purpose chicken products? How can consumer attitudes be clustered? 


\section{Theoretical Approaches}

\section{Understanding Acceptability}

Following the definition proposed by Busse and Siebert (2018), we define the acceptability of sustainability innovations as a complex and dynamic issue that deals with mutable decision processes. These processes are guided by value-based arguments and formed in intrapersonal relationships. These so-called acceptability decisions are products of the interactions between an actor, the specific acceptability object, other actors or groups, and the socio-economic, cultural, and political context (cf. Busse and Siebert 2018; Lucke 1995). Acceptability involves not only individual choices but also underlying social values and norms, shared routines, the perceived importance of things, etc. (cf. Spaargaren 2011; Schatzki 2001; Collins 2004). Nonetheless, social practices become visible in individual decisions. These decisions can be of a particular degree, ranging from opposition and rejection to high acceptance or engagement. Therefore, acceptance is one possible outcome of a decision process and differs from acceptability (Busse and Siebert 2018; Fournis and Fortin 2017). Acceptability is a more complex and multifaceted concept that encompasses positive (e.g., high acceptance) and negative decision degrees (rejection) (Kahma and Matschoss 2017) and degrees of uncertainty (cf. Hitzeroth and Megerle 2013). Since each decision degree is based on different motivations (e.g., motivations for acceptance may differ from those for rejection), it is meaningful to differentiate between them to draw adequate policy and marketing implications. Thus, science and innovation practice can also benefit from knowledge about motivations that cause rejection or conditionbased decisions. Furthermore, acceptability can be studied at different motivation levels (attitude, action or long-term utilization level) (Busse and Siebert 2018). Our study focusses on the attitude level, which deals with people's internal judgements before acting. The attitude level is shaped by the concepts of knowledge, awareness, and assessment (ibid.) (Fig. 1).

Generally, our understanding of acceptability is in line with social practice theory-a holistic sociological approach about understanding everyday practices, shared behaviour routines, "lock-in effects," and behavioural changes (cf., e.g., Reckwitz 2002; Schatzki 2001; Brand 2010). According to Brand (2010), consumers' social practices are interwoven with the provisioning system of food (in our case, poultry production) and are decisively influenced by the system context (political regulations, public discourses, and macro-structural trends). This systemic perspective of social practice theory links it to system innovation theories, especially to the multi-level approach to sustainability innovations (Brand 2010; Spaargaren 2011; Geels 2002). The links between both theories are illustrated in Fig. 2. 


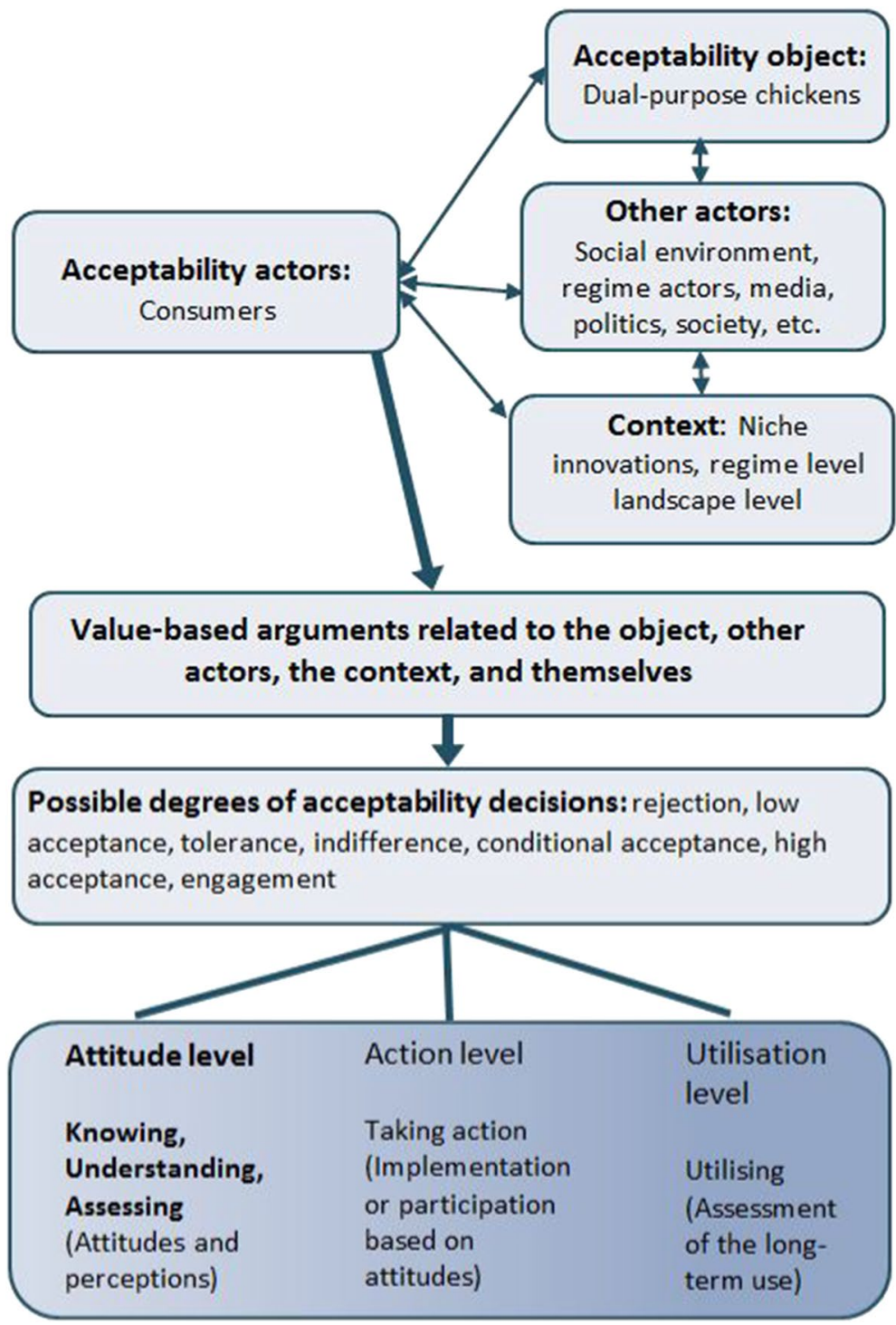

Fig. 1 Conceptual framework of acceptability with adoptions of the case study "dual-purpose chickens"

\section{Reflection of Poultry Production Within an MLP}

Dual-purpose chickens are an innovation answering the persisting structures and practices in egg production. To reflect on its potential, the MLP approach (Geels 2002; Geels and Schot 2007) provides a systemic understanding. Geels 2002 distinguishes between three interwoven levels of a socio-technical system: the "landscape level", the "regime level", and the "niche level". Interplay on all three 

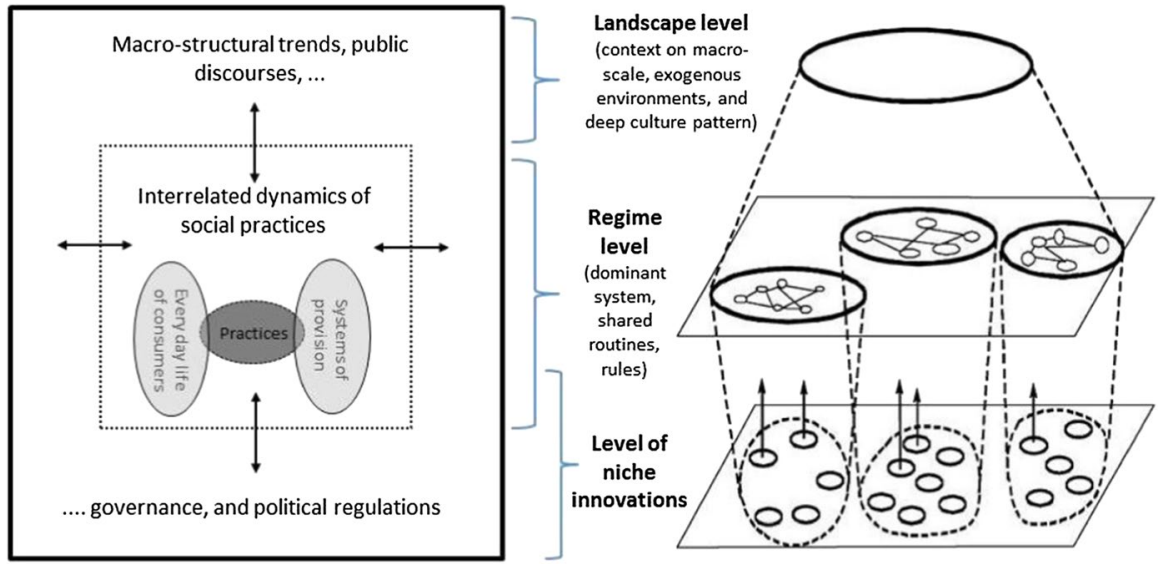

Fig. 2 Links between social practice theory (according to Brand 2010) and MLP (according to Geels 2002)

levels is necessary to promote the change of an existing system (Hörisch 2018). The landscape level considers the broad context of macro-scale, exogenous environments, long-term trends (societal, political, and economic), and deep cultural patterns, which are often difficult to change (Geels and Schot 2007). In our case, influences on the landscape level are the medial presence of animal welfare and discussion about prohibiting the killing of day-old chicks and the socio-political pressure to develop alternatives. The regime level refers to the established and mostly stable system where shared routines, rules and norms guide and affect the activities of regime actors (Geels 2002). At the regime level, the industrialized poultry production system, with a focus on high performance with specialized chicken varieties, is still dominant (Diehl 2016). This system is a part of the economies of scale. Potential alternatives to the problem of killing day-old chicks (in ovo determination, "lay hen brother" and dual-purpose chicken production) are innovations at the niche level. Schot and Geels (2008) define niches as "protected spaces that allow nurturing and experimentation with co-evolution of technology, user practices and regulatory structures". Dual-purpose chicken production (e.g., "ei care") is an agro-environmental innovation that seeks to change the dominant system into a more sustainable one (Diehl 2016). Innovations encompassing a substantial change in all value chain elements (farm management, production system, supply, processing, marketing, etc.) to foster a transformation towards sustainability are called system innovation (Elzen and Wieczorek 2005; Geels 2005). The conditions at the landscape and regime levels are very challenging for system innovations at the niche level (Diehl 2016). To create shifts at the regime level, an extension from a technological niche to a "market niche" is necessary (Schot and Geels 2008; Geels and Schot 2007). "Market niche" means increasing the market share to more than 5\% of market share (Geels and Schot 2007, 405 on the basis of Rogers 1995). As such, to build a market niche with dual-purpose initiatives that 
supports regime changes, knowledge about consumers' acceptability (attitudes and consumer segmentation) is needed.

\section{Methods and Materials}

\section{Data Collection}

Our survey was motivated by a small-scaled, regional, and organic farming initiative called "ei care" (see introduction) that was introduced in 2012 in the German federal states of Berlin and Brandenburg. We conducted 1000 telephone interviews (CATI-Computer Assisted Telephone Interviewing) with consumers in 2016. All participants were over the age of 18 and lived in Berlin or the Federal State of Brandenburg (Germany). The standardized interviews and the pretest $(n=50)$ were carried out by a market and polling research institute (forsa $\mathrm{GmbH}$ ). Consumers were selected with random sampling. The questionnaire contained a total of 43 questions/items, which were mainly closed questions with a small number of openended questions. Each interview took approximately $20 \mathrm{~min}$. In addition to items on acceptability conditions, the questionnaire also encompassed further aspects such as consumer purchase patterns, willingness to pay, and socio-demographic data. The set of questions about consumer attitudes towards chick killing and dual-purpose chickens (as relevant for this paper) were part of the broader questionnaire. The questionnaire design and the selected criteria for conditions for potential purchase

Table 1 Item selection criteria for question on conditions for potential purchase of dual-purpose chickens as basis for cluster analysis

\begin{tabular}{|c|c|c|c|}
\hline Items $^{\mathrm{a}}$ & Prestudy ${ }^{b}$ & $\begin{array}{l}\text { Expert } \\
\text { interviews }\end{array}$ & Literature \\
\hline Taste & $X$ & & Rana and Paul (2017) \\
\hline Price & $X$ & $\mathrm{X}$ & Rana and Paul (2017) \\
\hline Availability of the products & $X$ & & Grimmer et al. (2016) \\
\hline Labelling (type of label) & $X$ & & Rana and Paul (2017), Grunert et al. (2014) \\
\hline Trust information & & $\mathrm{X}$ & Hsu and Chen (2014) \\
\hline Trust in label & $X$ & $X$ & Janssen and Hamm (2014) \\
\hline Regionality & $\mathrm{X}$ & $\mathrm{X}$ & $\begin{array}{l}\text { Howard and Allen (2010), Zander and Hamm } \\
\text { (2010) }\end{array}$ \\
\hline Fair prices for farmers & & $\mathrm{X}$ & Howard and Allen (2010), Rana and Paul (2017) \\
\hline Agricultural biodiversity & & $X$ & Rana and Paul (2017), Zander and Hamm (2010) \\
\hline $\begin{array}{l}\text { Products from small and } \\
\text { diversified operating } \\
\text { farms }\end{array}$ & & $\mathrm{X}$ & Rana and Paul (2017) \\
\hline
\end{tabular}

${ }^{\mathrm{a}}$ For a complete formulation of items, consult Table 4

${ }^{b}$ Prestudy with face-to-face interviews conducted in an organic food market $(n=36)$

${ }^{c}$ Expert interviews with coordinators of the regional dual-purpose chickens initiative "ei care" (focus was on the "additional sustainability values" of "ei care" in comparison to organic farming standards) 


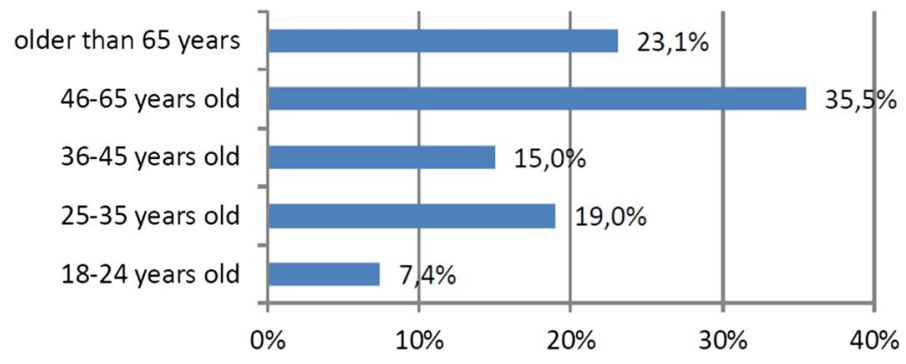

Fig. 3 Age structure of the sample $(n=1000)$

are based on a literature review, expert interviews, and a face-to-face prestudy $(\mathrm{n}=36)$ (Table 1). To identify consumer groups, a question about conditions for potentially buying dual-purpose chicken products was used.

\section{Sample Characteristics}

The resulting sample encompasses 583 people from Berlin and 417 from Brandenburg. A total of 514 women and 486 men were interviewed. All ages were represented in the sample (Fig. 3). The largest age group (35.5\% of participants) ranged from 46 to 65 years old, and the smallest group (7.4\% of participants) was 18 to 24 years old. Among survey participants, $41 \%$ had a higher-education degree (university or applied university), 36\% had completed vocational training, 5\% had not finished vocational training, and $4 \%$ were still in vocational training (9\% had another degree, and $3 \%$ did not provide this information).

\section{Data Analysis}

We used descriptive statistics to weight the sample according to region and crossweight it according to age and gender in SPSS (IBM Corp 2016). We then used cluster analysis to identify consumer groups based on their criteria for purchasing dual-purpose chicken products. Participants who stated during the survey that they would not buy dual-purpose chicken products ("Buying these products is out of the question for me") were excluded from cluster analysis $(n=21)$. Cluster analysis is a frequently used method for identifying groups in survey and multivariate data (Backhaus et al. 2008). All survey data was categorical and was either in agreement or disagreement with the question items, which we recoded into 1 (agree) and 0 (disagree). Since all values had the same scale, we did not transform the data. We used agglomerative hierarchal cluster analysis, which starts with single data points and successively groups these points together based on their similarity (Legendre and Legendre 2012). To cluster the points, we used Gower dissimilarities as the measure of association and Ward's clustering method. Gower dissimilarity is a symmetrical index for nominal, ordinal, and (a)symmetric binary data (Gower 1971). 
Ward's clustering method produces clear group structures with easily interpretable clusters. This method finds clusters by minimizing the variance to the geometric centroids of the groups (Alkarkhi and Alqaraghuli 2019). To better understand the differences between clusters, we selected other questionnaire items including behaviour (frequency of chicken meat and egg consumption and where chicken meat and eggs were purchased) and socio-economic data (gender, age, number of people in household, and income). We created contingency tables with the data and then used Chi square tests to test the relationships in the tables. All statistical analyses were conducted using the $\mathrm{R}$ interface ( $\mathrm{R}$ Core Team 2016). We used the $\mathrm{R}$ package for cluster analysis (Maechler et al. 2018).

\section{Results}

\section{Knowledge and Assessment of Killing of Day-Old Chicks and of Dual-Purpose Chickens}

The practice of killing of day-old chicks was known by $70 \%$ of the study participants, regardless of place of residence, age, and gender. One exception was the age group between 18 and 24, which had only $46 \%$ of informed participants. Eighteen percent stated that they had already heard about this practice but could not explain it. The remaining $12 \%$ had never heard about this practice. After a neutral explanation about the practice of killing day-old chicks was offered, participants were asked to ethically assess this practice. It turned out that the vast majority (almost 80\%) regard this issue as "very problematic" $(67 \%)$ or problematic $(12 \%)$ (Table 2$)$.

The following questions concerned the knowledge of potential and currently discussed alternatives to killing the chicks. Roughly half of study participants did not know about in ovo sexing and "lay hen brother" rearing. Moreover, dual-purpose

Table 2 Ethical assessment of the common practice of killing day-old chicks in poultry production on a 7-point Likert scale (see Busse and Siebert 2017)

\begin{tabular}{llllll}
\hline & All & Brandenburg & Berlin & Male & Female \\
\hline Very problematic (1) & $67 \%$ & $67 \%$ & $67 \%$ & $59 \%$ & $74 \%$ \\
$(2)$ & $12 \%$ & $10 \%$ & $13 \%$ & $13 \%$ & $11 \%$ \\
$(3)$ & $9 \%$ & $9 \%$ & $9 \%$ & $11 \%$ & $7 \%$ \\
$(4)$ & $4 \%$ & $4 \%$ & $4 \%$ & $5 \%$ & $3 \%$ \\
$(5)$ & $3 \%$ & $3 \%$ & $3 \%$ & $4 \%$ & $2 \%$ \\
$(6)$ & $1 \%$ & $2 \%$ & $1 \%$ & $2 \%$ & $1 \%$ \\
Completely unproblematic (7) & $2 \%$ & $3 \%$ & $1 \%$ & $4 \%$ & $1 \%$ \\
I don't know/no answer & $2 \%$ & $2 \%$ & $2 \%$ & $3 \%$ & $1 \%$ \\
Sum & $100 \%$ & $100 \%$ & $100 \%$ & $101 \%$ & $100 \%$ \\
Mean & 1.7 & 1.8 & 1.7 & 2.0 & 1.5 \\
Standard derivation & 1.38 & 1.48 & 1.30 & 1.57 & 1.13 \\
\hline
\end{tabular}




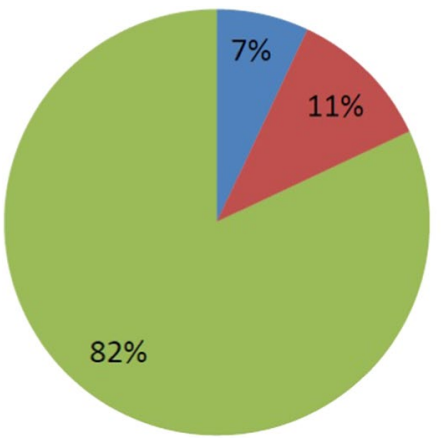

I have heard of dual purpose chickens, but I cannot explain.

I know dual purpose chickens and I know what it means.

I do not know dual purpose chickens

Fig. 4 Knowledge of dual-purpose chicken production as potential alternative to killing day-old chicks

Table 3 Assessment of level of information on animal welfare and ethical issues in poultry production on a 7-point Likert scale (see Busse and Siebert 2017)

\begin{tabular}{llllll}
\hline & All (n=979) & Brandenburg & Berlin & Male & Female \\
\hline Feel very well informed (1) & $5 \%$ & $5 \%$ & $4 \%$ & $3 \%$ & $6 \%$ \\
$(2)$ & $8 \%$ & $8 \%$ & $8 \%$ & $9 \%$ & $7 \%$ \\
$(3)$ & $22 \%$ & $23 \%$ & $21 \%$ & $23 \%$ & $20 \%$ \\
$(4)$ & $18 \%$ & $18 \%$ & $18 \%$ & $19 \%$ & $17 \%$ \\
$(5)$ & $18 \%$ & $16 \%$ & $19 \%$ & $17 \%$ & $19 \%$ \\
$(6)$ & $11 \%$ & $10 \%$ & $12 \%$ & $11 \%$ & $12 \%$ \\
Feel completely uninformed (7) & $18 \%$ & $19 \%$ & $17 \%$ & $18 \%$ & $17 \%$ \\
I don't know/no answer & $1 \%$ & $1 \%$ & $1 \%$ & $0 \%$ & $1 \%$ \\
Sum & $101 \% \mathrm{a}$ & $100 \%$ & $100 \%$ & $100 \%$ & $99 \%$ \\
Mean & 4.4 & 4.4 & 4.4 & 4.4 & 4.4 \\
Standard derivation & 1.74 & 1.78 & 1.71 & 1.71 & 1.74 \\
\hline
\end{tabular}

${ }^{a}$ Value of $101 \%$ is caused by rounding up decimal places to full percentages
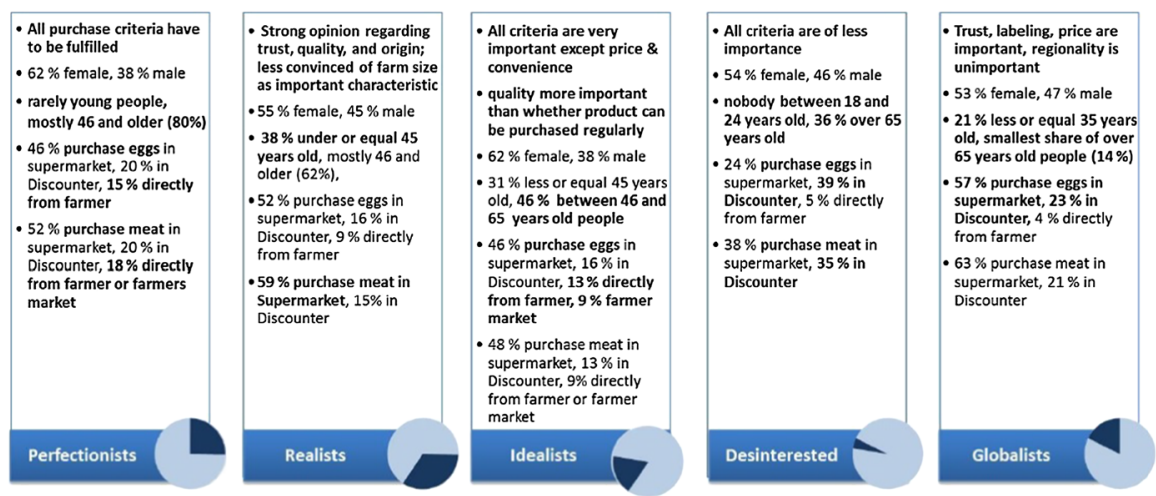

Fig. 5 Description of clusters using the results of cluster analysis (Table 4) and purchasing routines and socio-economic data (Table 5). Pie charts show the cluster size in comparison to the total sample 


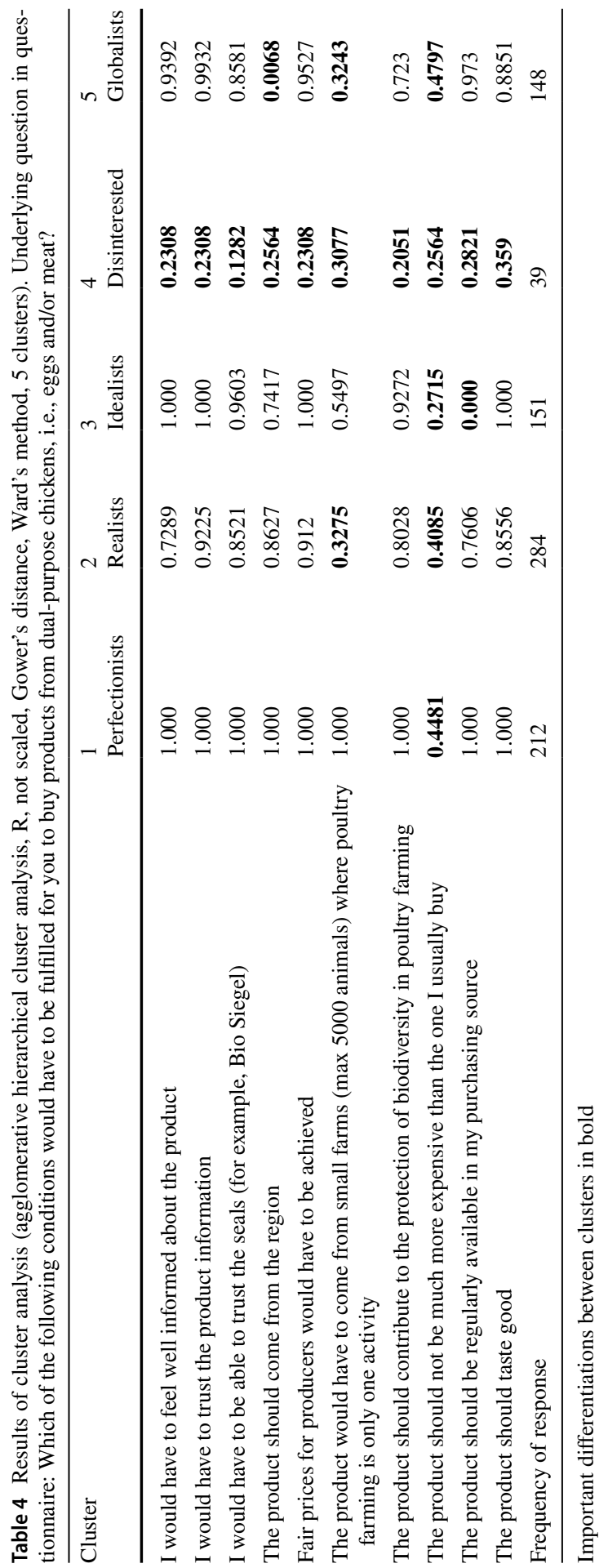


Table 5 Chi square test results on relationships between clusters and purchasing routines and socio-economic factors

\begin{tabular}{llrl}
\hline Factor & $\chi^{2}$ & $d f$ & $p$ values \\
\hline How frequently do you eat eggs? & 31.114 & 24 & 0.1497 \\
Where do you purchase eggs? & $\mathbf{7 7 . 7 4 4}$ & $\mathbf{3 6}$ & $\mathbf{6 . 7 1 9 e - 0 5}$ \\
How frequently do you eat meat? & 25.519 & 24 & 0.378 \\
Where do you purchase meat? & $\mathbf{4 3 . 1 8 5}$ & $\mathbf{2 4}$ & $\mathbf{0 . 0 0 9 4 7 5}$ \\
Gender & $\mathbf{1 0 . 2 6 2}$ & $\mathbf{4}$ & $\mathbf{0 . 0 3 6 2 4}$ \\
Age & $\mathbf{4 0 . 7 5 6}$ & $\mathbf{1 6}$ & $\mathbf{0 . 0 0 0 6 0 3 1}$ \\
How many people are in your household? & 17.664 & 20 & 0.6096 \\
What is your highest level of completed education? & 37.351 & 32 & 0.2366 \\
What is your monthly income? & 41.192 & 52 & 0.8593 \\
\hline
\end{tabular}

Significant relationships, in bold, were defined for those factors where the Chi square test resulted in a $p$ value of $<0.05$

chicken production was even less familiar. Most of the study participants (82\%) had never heard about this form of chicken husbandry (Fig. 4).

After having been taught about dual-purpose chicken production, half of the surveyed consumers assessed it as a "real alternative to current practice, which should be further promoted". Nevertheless, more than a third (37\%) pointed out that "I like the concept, but I do not think it will be adopted on a large scale". Six percent "do not like the concept and prefer another alternative". Another 11\% stated "I don't have an opinion on it". The last percent did not give an answer or indicated "I don't know". The majority felt insufficiently informed about welfare issues in poultry production (killing of day-old chicks and its alternatives) (Table 3). Approximately 60\% would like to obtain more information.

\section{Consumer Attitudes Concerning Dual-Purpose Chickens}

After exploring the results of 3-7 clusters and consulting the scree plot, we found that 5 clusters were the most appropriate and best explained patterns in the data (Fig. 5). Survey respondents in cluster $1(n=212)$ had a mean of 1 across all question items except for the item regarding product price. Due to these strong responses, we categorized this cluster as "the sustainability perfectionists," since all product characteristics were important. The respondents in cluster $2(n=284)$ were generally more positive about all question items, except that when it came to farm size, they generally did not consider size as an important factor contributing to sustainability. Given their generally less strong responses, we categorized this cluster as "the sustainability realists." In cluster $3(n=151)$, the defining characteristic was that price and convenience were not important, so we characterized this cluster as "the sustainability idealists," since quality and trust were more important than convenience and price. In cluster 4, respondents had a very low mean value for each of the question items, so we categorized them as "the disinterested" $(n=39)$. The last cluster, cluster $5(n=148)$, showed positive responses for most question items except for the regional component of the product and the farm size, 
suggesting that these are "the global sustainability supporters." Trust and quality are important, but where the products come from is less important. The one question item that seemed to be unclear to survey participants was regarding farm size as a contributing factor to food product sustainability. This lack of clarity was apparent through the large variation in the mean value of the responses (clusters 2-5). In this case, size and sustainability are not clearly related for most of the consumers.

Chi square tests on contingency tables with behavioural and socio-economic factors revealed that clusters were significantly different based on where (which type of store or source) eggs or meat were purchased/obtained, as well as on gender and age. None of the other factors differed significantly between clusters.

\section{Discussion}

\section{Attitudes Regarding Killing of Day-Old Chicks and Dual-Purpose Chickens}

Our survey shows that $70 \%$ of the participants are aware of the killing of dayold chicks. Brümmer et al. (2018) confirm that the practice is well known among German citizens. In an earlier survey with the Dutch public, Leenstra et al. (2011) revealed that $58 \%$ of the respondents did not know about the killing of day-old chicks. The results of our study exposed a high ratio of people $(67 \%)$ who consider the practice of killing chicks very problematic. For the Netherlands, Leenstra et al. (2011) found that $36 \%$ of their respondents assessed the practices as 'bad' or 'very bad'. Seven years later, another survey by Gremmen et al. (2018) shows an increased share of Dutch respondents (47\%) who assert the need for alternatives and a stop to this practice. These numbers suggest that killing male day-old chicks has become a topic of increasing relevance to consumers. A generally growing awareness among consumers about ethical questions in food production and their call for improved animal welfare supports this finding (Heise and Theuvsen 2017; Hatt et al. 2016). Our results indicate a problematization of the killing of day-old chicks by consumers, which could serve as a solid basis to introduce alternatives to killing the day-old chicks, such as dual-purpose chickens. As previous studies have shown, the challenging of prevailing practices often starts with critical social discourses and increased media attention (e.g., JaegerErben et al. 2015; Brand 2010).

Furthermore, our study confirms that rearing dual-purpose chickens is not well known (Brümmer et al. 2018; Gremmen et al. 2018). Only 7\% of our respondents were familiar with the concept. However, when the concept was explained to them, the vast majority of the respondents considered it to be positive. However, mainly due to the higher price, a third of our respondents were sceptical that this practice would be successfully established on the market (see also Brümmer et al. 2018; Leenstra et al. 2011). 


\section{Cluster Analysis: Market Potential for Dual-Purpose Chickens}

The stated concern of consumers about animal welfare issues does not automatically translate into high sales figures of products where aspects such as ethical animal husbandry are considered (Boogaard et al. 2011). Various aspects determine purchasing criteria: in addition to attitudes concerning agriculture and welfare issues, access to and trust in product information and sociodemographic characteristics as well as shopping habits play important roles (Toma et al. 2012; Heise and Theuvsen 2017). Further reasons for not buying ethically produced food despite the respective attitude can also result from a lack of availability and especially from consumers' misinterpretation of production information (Vecchio and Annunziata 2012).

Distinguishing socio-economic factors for the five identified clusters were 'store type' (meaning where eggs or meat were obtained), 'gender' and 'age'. Other factors such as 'income' and 'level of education' did not significantly differ between clusters. The relationship between sociodemographic characteristics and shopping behaviour or attitudes varies from study to study (Heise and Theuvsen 2017; Vermeir and Verbeke 2006). While some scholars confirm our findings (Heise and Theuvsen 2017; Vanhonacker et al. 2013), others assume above-average income and education as characteristic of ethical consumers (Vecchio and Annunziata 2012; Vermeir and Verbeke 2006).

Except for the 'disinterested' and 'globalists', the other clusters all seem to contain potential customers. Most promising to be addressed by marketing measures appears to be the group of 'idealists'. This group stated a willingness to accept a higher price and irregular availability of the product. With a share of $18 \%$ of all respondents, there might be a good chance to successfully establish a market niche for dual-purpose chicken products. A further target group is the 'realists'. Both 'realists' and 'idealists' more often purchase eggs and meat in the supermarket than at discounters or directly from farmers. While this is also the case for the 'perfectionists', this latter group appears to be extremely demanding. They want the "perfect" product, but their willingness to adequately pay for it is rather low. The group of 'globalists' does not seem to be a suitable target group. They predominantly shop at discounters but demand that the product be available in "their store" at a favourable price. The additional value of regionality does not play a role in their consumer behaviour.

The small cluster of 'disinterested' individuals seems to be least addressable with marketing. This group exhibits the lowest values across all buying criteria. Hence, it will be difficult to convince these customers to buy dual-purpose products. Marketing should recognize that some consumer groups do not want to be informed (Boogaard et al. 2011; Vecchio and Annunziata 2012) or change their habits (Shafie and Rennie 2012; Vermeir and Verbeke 2006).

\section{Recommendations for Marketing Strategy and the Development of a Market Niche}

As indicated by Geels and Schot (2007), the development of a market niche (meaning a market share of at least 5\%) is necessary to achieve changes at the regime level. Nevertheless, the lack of knowledge about the dual-purpose approach and 
how it is actually implemented could create acceptability issues among customers beyond willingness to pay, thereby posing a major barrier to implementation. The study by Brümmer et al. (2018) revealed that some customers were concerned that dual-purpose chickens are genetically engineered breeds. In general, dual-purpose chickens are a complex product that is not easily understandable (see also Gremmen et al. 2018). This product requires special communication and marketing efforts to demonstrate its sustainability, originality and ethical advantages compared to conventional poultry production and competing organic products (cf. Hatt et al. 2016; Lamine 2015). This approach could justify its higher price but could also promote new practices such as a longer cooking duration (due to differing meat properties of the breeds) and a more balanced consumption of eggs and meat to avoid food waste. The latter refers to a distribution of eggs and meat that aims at a sale ratio of 180 eggs per hen and one male chicken.

Marketing should make consumers aware that their decisions have an impact and that they can contribute to the solution of sustainability problems (Toma et al. 2012; Fink et al. 2018). This way, customers associate their consumption patterns with a positive emotional feeling (Spaargaren 2011; Vega-Zamora et al. 2018). The consideration of animal welfare aspects has high potential to appeal to consumers (Nocella et al. 2010). Furthermore, our study revealed that in four out of five clusters, it is important to the consumers that farmers receive a fair share of the retail price (cf. Howard and Allen 2010). Especially in initiatives where the products are sold only regionally (e.g., ei care), the direct support of a producer through consumers could be emphasized. Regional origin played a major role for the three biggest clusters, the "perfectionists", "the realists" and "the idealists". In addition, more collaborative approaches that foster the direct relationship between producers and consumers appear promising (e.g., Dumont et al. 2016; Spaargaren 2011). By means of such participative processes, consumers become promoters of the innovation, the intention-behaviour gap can be bridged (Fink et al. 2018; Vega-Zamora et al. 2018), and the complex innovation of dual-purpose chicken can be more comprehensively communicated and understood.

It is noteworthy that trust and product information were crucial across all consumer clusters. There are many buying criteria and product specifications that consumers can only experience after the first purchase (e.g., taste) or cannot verify by themselves at all (e.g., compliance with animal welfare policies) (Napolitano et al. 2010). Thus, access to and trust in product information are often identified as main determinants for the willingness to buy more animal-friendly products (Nocella et al. 2010; Toma et al. 2012). For dual-purpose chicken products in particular, clear labelling that provides consumer information has been identified as the most frequent purchase criterion (Brümmer et al. 2018). However, other studies revealed that an information overload should be avoided (Verbeke 2009). For egg labels, Vecchio and Annunziata (2012) found that customers have little familiarity with them, which means that important information might not reach a substantial share of potential customers. Quality in terms of taste is another important purchase criterion across all identified clusters. It is therefore very important to provide the consumers with arguments that convince them try the dual-purpose products for the first time. Apart from marketing and the provision of product information, it is crucial for the development of a market niche to consider the availability 
of the product to overcome low sales (Brand 2010) and the attitude-behaviour gap (Vermeir and Verbeke 2006). In cities, this approach could be accomplished by including dual-purpose chicken products into the assortment of more organic supermarkets, whereas in the countryside, direct marketing or small organic grocery stores could help to increase availability.

\section{Implications from an MLP}

Our results also have policy implications for the transition of prevailing practices in poultry production when regarded through an MLP. On the landscape level, the increasing media presence and the German court proceeding about killing day-old chicks in 2016 confirms our result of a growing awareness in the public. Such moderate and long-lasting pressure at the landscape level can lead to the de-alignment of the regime and promote the development of the competing niche innovations of in ovo sexing, "lay hen brothers", and dual-purpose chickens. Generally, niche innovations, which are compliant with existing rules, have the most potential to provoke changes or even substitute for the current system than system innovation or innovations that are not fully developed (Geels and Schot 2007). Dual-purpose chickens have the smallest chance to bring about regime change because this innovation is a system innovation that is, moreover, still not sufficiently developed (cf. "Reflection of Poultry Production

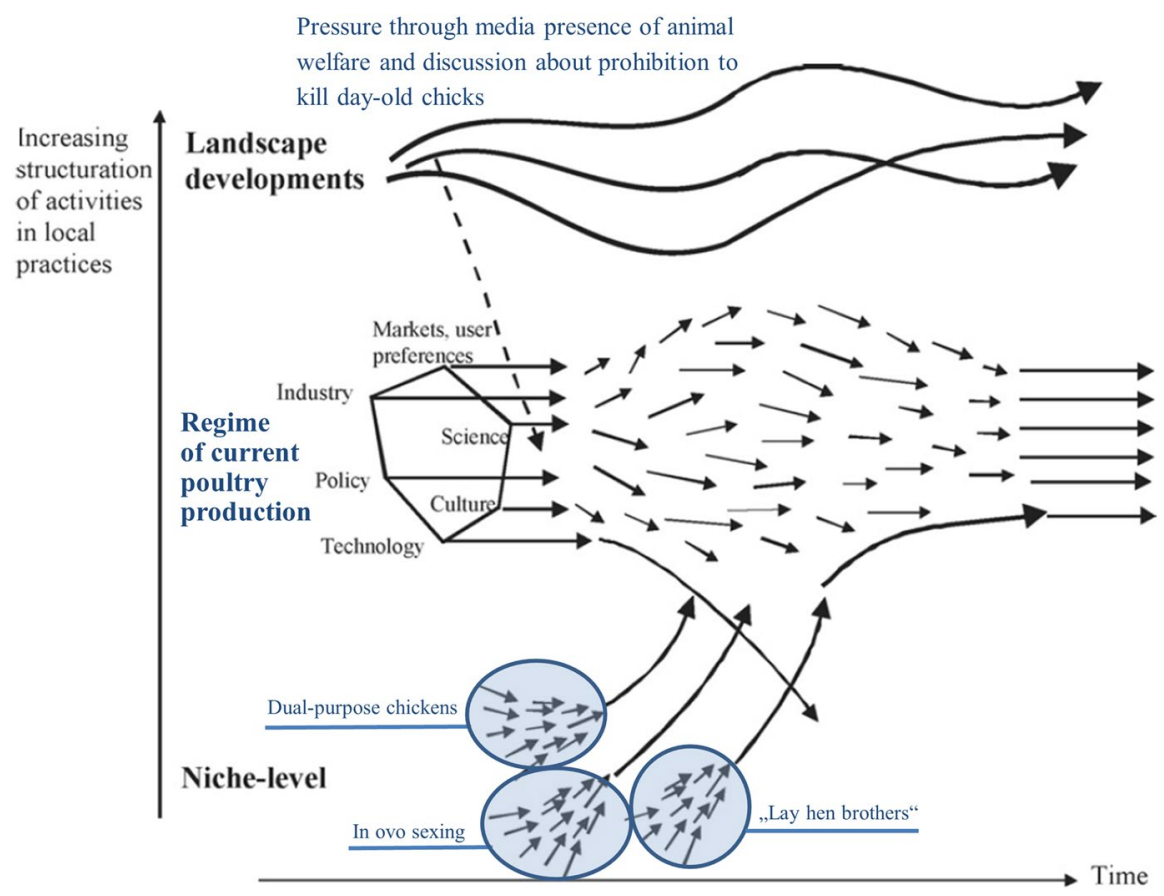

Fig. 6 De-alignment and re-alignment pathway by Geels and Schot $(2007,409)$ illustrating the probable transition process of the poultry production (own modifications) 
Within an MLP" section). In ovo sexing and "lay hen brothers" are innovations that are compliant with most prevailing regime rules (Diehl 2016), and have, therefore, more potential to become dominant and to re-align the regime. Apart from this assumption, each of these alternative niche innovations has its supporters and proponents among consumers (Gremmen et al. 2018). This probable development of dual-purpose chicken production corresponds to the transition pathway of "de-alignment and re-alignment" described by Geels and Schot (2007) (Fig. 6). A system change would require the supply of dual-purpose chickens by breeders and hatcheries, structural adaptation in value chain businesses (hatcheries, slaughterhouses, processing, and logistics), acceptance among farmers and a new consumer culture that accepts premium prices of the products (Zander and Hamm 2010) and that values the efforts of the social entrepreneurs who foster such a transition (Hörisch 2018). A changing consumer culture is expressed in the large share of surveyed consumers who problematized the killing of male chicks and considered dual-purpose chicken as a "real alternative to current practice". Whether these expressed values actually translate into changing purchase decisions is an issue that cannot be answered from our results. However, favourable consumer attitudes are only one component of successful niche innovations.

\section{Conclusions}

The aim of this article was to analyse the acceptability and potential of dual-purpose chickens to build a market niche. Dual-purpose chickens are discussed as an alternative option to avoid the prevailing practice of killing of day-old chicks. The results of our survey showed that the killing of day-old chicks is a well-known practice that is considered very problematic by a vast majority. This awareness depicts a favourable basis for the introduction of alternatives to the prevailing practice. The cluster analysis revealed a segmentation of consumers into five groups ('perfectionists', 'idealists', 'realists', 'disinterested' and 'globalists'). Three of these five groups seem suitable and sufficiently large to create a viable market niche. Nevertheless, the successful establishment of dual-purpose chickens on the market will need special communication and marketing efforts to demonstrate its additional value in comparison to "lay hen brothers" and other competing products. Overall, the clusters exhibit different shopping preferences that involve price, store type and availability but also commonalities such as regionality or fair producer prices. Our findings can help to address these preferences accordingly to create a customer base of people who understand themselves as actors in a transition process.

However, from an MLP, the preferences and attitudes of consumers that we explored in this study are only one component of a socio-technical regime. For a change in the prevailing poultry production system to occur, other elements (legislation, science, culture, technology, etc.) must also be met. An exploration of the interplay of all different regime actors and elements beyond the dual-purpose chicken niche would be an interesting issue to address with future research and would enable a more comprehensive assessment of the transition potential for the poultry sector. Regarding the niche level, dual-purpose chickens seem to have a competitive disadvantage compared to regime-compliant alternatives. However, the market shares of 
the different alternatives are small at this point, and different consumers prefer distinct alternatives to the killing of male chicks. Consequently, we conclude that none of the alternatives emerges as the single driver of regime transformation. External impetuses such a ban on the killing of male chicks could act as a decisive driver for the establishment of one or several of the alternative practices, but overall, it is more likely that the different alternatives can jointly contribute to change the prevailing practices incrementally.

Acknowledgments Funding from the Federal Ministry of Education and Research, Germany (BMBF) has supported this work (funding code 033L145D).

Data Information The survey data is available on Open Research Data (https://www.doi.org/10.4228/ ZALF.DK.106).

\section{Compliance with Ethical Standards}

Conflict of interest The authors declare that they have no conflict of interest.

Informed Consent Informed consent was obtained from all individual participants included in the study.

Open Access This article is distributed under the terms of the Creative Commons Attribution 4.0 International License (http://creativecommons.org/licenses/by/4.0/), which permits unrestricted use, distribution, and reproduction in any medium, provided you give appropriate credit to the original author(s) and the source, provide a link to the Creative Commons license, and indicate if changes were made.

\section{References}

Alkarkhi, A. F. M., \& Alqaraghuli, W. A. A. (2019). Chapter 11-cluster analysis. In A. F. M. Alkarkhi \& W. A. A. Alqaraghuli (Eds.), Easy statistics for food science with R (pp. 177-186). New York: Academic Press.

Backhaus, K., Erichson, B., Plinke, W., \& Weiber, R. (2008). Multivariante Analysemethoden. Eine anwendungsorientierte Einführung (12th ed.). Berlin: Springer.

Boogaard, B. K., Bock, B. B., Oosting, S. J., Wiskerke, J. S. C., \& van der Zijpp, A. J. (2011). Social acceptance of dairy farming: the ambivalence between the two faces of modernity. Journal of Agricultural and Environmental Ethics. https://doi.org/10.1007/s10806-010-9256-4.

Brand, K.-W. (2010). Social practices and sustainable consumption: Benefits and limitations of a new theoretical approach. In M. Gross \& H. Heinrichs (Eds.), Environmental sociology: European perspectives and interdisciplinary challenges (pp. 217-236). Dordrecht: Springer. https://doi. org/10.1007/978-90-481-8730-0_13.

Bruijnis, M. R. N., Blok, V., Strassen, E. N., \& Gremmen, H. G. J. (2015). Moral “Lock-In"' in responsible innovation: The ethical and social aspects of killing day-old chicks and its alternatives. Journal of Agricultural and Environmental Ethics. https://doi.org/10.1007/s10806-015-9566-7.

Brümmer, N., Christoph-Schulz, I., \& Rovers, A.-K. (2018). Consumers' perspective on dual-purpose chickens. In Proceedings in system dynamics and innovation in food networks 2017. https://doi. org/10.18461/pfsd.2017.1717.

Busse, M., \& Siebert, R. (2017). Einstellungen zu ethischen Aspekten in der Geflügelhaltung. Presentation at 14th Wissenschaftstagung Ökologischer Landbau, Freising-Weihenstephan (Germany), März 7-10, 2017. Retrieved June 16, 2019, from http://orgprints.org/31888/1/Einstellungen\%20zu\%20eth ischen\%20Aspekten\%20in\%20der\%20Gefl\%C3\%BCgelhaltung.pdf.

Busse, M., \& Siebert, R. (2018). Acceptance studies in the field of land use-a critical and systematic review to advance the conceptualization of acceptance and acceptability. Land Use Policy. https:// doi.org/10.1016/j.landusepol.2018.05.016. 
Collins, R. (2004). Interaction ritual chains. Princeton: Princeton University Press.

Damme, K. (2015). Economics of dual-purpose breeds - a comparison of meat and egg production using dual-purpose breeds versus conventional broiler and layer strains. Lohmann Information, 50(2), 4-9.

Diehl, K. (2016). Sustainability assessment of agro-ecological innovations at territorial and value chain scale. In 12th IFSA symposium 2016, July 12-15, 2016, Harper Adams University, UK.

Dumont, A. M., Vanloqueren, G., Stassart, P. M., \& Baret, P. V. (2016). Clarifying the socio-economic dimensions of agroecology: between principles and practices. Agroecology and Sustainable Food Systems. https://doi.org/10.1080/21683565.2015.1089967.

Elzen, B., \& Wieczorek, A. (2005). Transitions towards sustainability through system innovation. Technological Forecasting and Social Change. https://doi.org/10.1016/j.techfore.2005.04.002.

Fink, L., Ploeger, A., \& Strassner, C. (2018). Participative processes as a chance for developing ideas to bridge the intention-behavior gap concerning sustainable diets. Sustainability. https://doi. org/10.3390/su10124434.

Fournis, Y., \& Fortin, M.-J. (2017). From social "acceptance" to social "acceptability" of wind energy projects: towards a territorial perspective. Journal of Environmental Planning and Management. https://doi.org/10.1080/09640568.2015.1133406.

Galli, R., Koch, E., Preusse, G., Schnabel, C., Bartels, T., Krautwald-Junghanns, M.-E., et al. (2017). Contactless in ovo sex determination of chicken eggs. PLOS ONE. https://doi.org/10.1371/journ al.pone.0192554.

Geels, F. W. (2002). Technological transitions as evolutionary reconfiguration processes: A multi-level perspective and a case study. Research Policy, 31, 1257-1274.

Geels, F. W. (2005). Technological transitions and system innovations: A co-evolutionary and socio-technical analysis. Cheltenham: Edward Elgar Publishing Ltd.

Geels, F. W., \& Schot, J. (2007). Typology of sociotechnical transition pathways. Research Policy. https:// doi.org/10.1016/j.respol.2007.01.003.

Gower, J. C. (1971). A general coefficient of similarity and some of its properties. Biometrics, 27, $857-874$.

Gremmen, B., Bruijnis, M. R. N., Blok, V., \& Stassen, E. N. (2018). A public survey on handling male chicks in the Dutch egg sector. Journal of Agricultural and Environmental Ethics. https://doi. org/10.1007/s10806-018-9712-0.

Grimmer, M., Kilburn, A. P., \& Miles, M. P. (2016). The effect of purchase situation on realized proenvironmental consumer behavior. Journal of Business Research. https://doi.org/10.1016/j.jbusr es.2015.10.021.

Grunert, K. G., Hieke, S., \& Wills, J. (2014). Sustainability labels on food products: Consumer motivation, understanding and use. Food Policy. https://doi.org/10.1016/j.foodpol.2013.12.001.

Hatt, S., Artru, S., Brédart, D., Lassois, L., Francis, F., Haubruge, É., et al. (2016). Towards sustainable food systems: The concept of agroecology and how it questions current research practices. A review. Biotechnology, Agronomy, Society and Environment, 20(S1), 215-224.

Heise, H., \& Theuvsen, L. (2017). What do consumers think about farm animal welfare in modern agriculture? Attitudes and shopping behaviour. International Food and Agribusiness Management Review. https://doi.org/10.22434/IFAMR2016.0115.

Hempel, C., \& Hamm, U. (2016). Local and/or organic: A study on consumer preferences for organic food and food from different origins. International Journal of Consumer Studies. https://doi. org/10.1111/ijcs.12288.

Hitzeroth, M., \& Megerle, A. (2013). Renewable energy projects: Acceptance risks and their management. Renewable and Sustainable Energy Reviews. https://doi.org/10.1016/j.rser.2013.07.022.

Hörisch, J. (2018). How business actors can contribute to sustainability transitions: A case study on the ongoing animal welfare transition in the German egg industry. Journal of Cleaner Production. https ://doi.org/10.1016/j.jclepro.2018.08.031.

Hörning, B., \& Häder, F. (2015). Zweinutzungshühner im Ökolandbau? Problematik, Pilotprojekte, Perspektiven. In Beiträge zur 13. Wissenschaftstagung Ökologischer Landbau (March 17-20, 2015, Eberswalde, Germany). Retrieved November 16, 2016, from http://orgprints.org/27070.

Howard, P. H., \& Allen, P. (2010). Beyond organic and fair trade? An analysis of ecolabel preferences in the United States. Rural Sociology. https://doi.org/10.1111/j.1549-0831.2009.00009.x.

Hsu, C.-L., \& Chen, M.-C. (2014). Explaining consumer attitudes and purchase intentions toward organic food: Contributions from regulatory fit and consumer characteristics. Food Quality and Preference. https://doi.org/10.1016/j.foodqual.2014.01.005. 
Icken, W., Schmutz, M., Cavero, D., \& Preisinger, R. (2013). Dual-purpose chickens: The breeder's answer to the culling of day-old male layers. In World's Poultry Science Journal: 9th European symposium on poultry welfare, Book of Abstracts 91.

Jaeger-Erben, M., Rückert-John, J., \& Schäfer, M. (2015). Sustainable consumption through social innovation: a typology of innovations for sustainable consumption practices. Journal of Cleaner Production. https://doi.org/10.1016/j.jclepro.2015.07.042.

Janssen, M., \& Hamm, U. (2014). Governmental and private certification labels for organic food: Consumer attitudes and preferences in Germany. Food Policy. https://doi.org/10.1016/j.foodp ol.2014.05.011.

Kahma, N., \& Matschoss, K. (2017). The rejection of innovations? Rethinking technology diffusion and the non-use of smart energy services in Finland. Energy Research \& Social Science. https://doi. org/10.1016/j.erss.2017.05.024.

Kaleta, E. F., \& Redmann, T. (2008). Approaches to determine the sex prior to and after incubation of chicken eggs and of day-old chicks. World's Poultry Science Journal, 64(3), 391-399.

Klerkx, L., Aarts, N., \& Leeuwis, C. (2010). Adaptive management in agricultural innovation systems: The interactions between innovation networks and their environment. Agricultural Systems. https:// doi.org/10.1016/j.agsy.2010.03.012.

Krautwald-Junghanns, M.-E., Cramer, K., Fischer, B., Förster, A., Galli, R., Kremer, F., et al. (2018). Current approaches to avoid the culling of day-old male chicks in the layer industry, with special reference to spectroscopic methods. Poultry Science. https://doi.org/10.3382/ps/pex389.

Lamine, C. (2015). Sustainability and resilience in agrifood system: Reconnecting agriculture, food and the environment. Sociologia Ruralis, 55(1), 41-61.

Leenstra, F., Munnichs, G., Beekman, V., Van den Heuvel-Vromans, E., Aramyan, L., \& Woelders, H. (2011). Killing day-old chicks? Public opinion regarding potential alternatives. Animal Welfare, 20(1), 37-45.

Leenstra, F. R., van Horne, P. L. M., \& Krimpen, M. M. (2010). Dual-purpose chickens, exploration of technical, environmental and economic feasibility. In Proceedings XIIIth European poultry conference, Tours, France.

Legendre, P., \& Legendre, L. (2012). Chapter 8-cluster analysis. In P. Legendre \& L. Legendre (Eds.), Developments in environmental modelling (pp. 337-424). Amsterdam: Elsevier.

Lucke, D. (1995). Akzeptanz. Legitimität in der "Abstimmungsgesellschaft” (2nd ed.). Opladen: Leske + Budrich.

Maechler, M., Rousseeuw, P., Struyf, A., Hubert, M., Hornik, K., Studer, M., Gonzalez, J., \& Kozlowski, K. (2018). Cluster: Cluster analysis basics and extensions. R package version 2.0.7-1.

Morgan, K., Marsden, T., \& Murdoch, J. (2006). Worlds of food. Place, power, and provenance in the food chain. Oxford: University Press.

Napolitano, F., Girolami, A., \& Braghieri, A. (2010). Consumer liking and willingness to pay for high welfare animal-based products. Trends in Food Science \& Technology. https://doi.org/10.1016/j. tifs.2010.07.012.

Nocella, G., Hubbard, L., \& Scarpa, R. (2010). Farm animal welfare, consumer willingness to pay, and trust: Results of a cross-national survey. Applied Economic Perspectives and Policy. https://doi. org/10.1093/aepp/ppp009.

Rana, J., \& Paul, J. (2017). Consumer behavior and purchase intention for organic food: A review and research agenda. Journal of Retailing and Consumer Services. https://doi.org/10.1016/j.jretconser .2017.06.004.

Raynolds, L. T. (2004). The globalization of agro-food networks. World Development. https://doi. org/10.1016/j.worlddev.2003.11.008.

Reckwitz, A. (2002). Toward a theory of social practices. A development in cultural theorizing. European Journal of Social Theory. https://doi.org/10.1177/13684310222225432.

IBM Corp. Released 2016. IBM SPSS statistics for windows, version 24.0. Armonk, New York: IBM Corp.

Schatzki, T. (2001). Introduction. Practice theory. In T. Schatzki, K. Knorr-Cetina, \& E. von Savigny (Eds.), The practice turn in contemporary theory (pp. 1-13). London: Routledge.

Schot, J., \& Geels, F. W. (2008). Strategic niche management and sustainable innovation journeys: Theory, findings, research agenda, and policy. Technology Analysis \& Strategic Management. https:// doi.org/10.1080/09537320802292651.

Shafie, F. A., \& Rennie, D. (2012). Consumer perceptions towards organic food. Procedia Social and Behvioral Sciences. https://doi.org/10.1016/j.sbspro.2012.07.034. 
Spaargaren, G. (2011). Theories of practices: Agency, technology, and culture: Exploring the relevance of practice theories for the governance of sustainable consumption practices in the new world-order. Global Environmental Change. https://doi.org/10.1016/j.gloenvcha.2011.03.010.

R Core Team. (2016). R: A language and environment for statistical computing. R Foundation for Statistical Computing, Vienna. Retrieved June 26, 2019, from www.R-project.org/.

Rogers, E. (1995). The diffusion of innovations (4th ed.). New York: Free Press.

Toma, L., Stott, A. W., Revoredo-Giha, C., \& Kupiec-Teahan, B. (2012). Consumers and animal welfare. A comparison between European Union countries. Appetite. https://doi.org/10.1016/j.appet .2011.11.015.

Vanhonacker, F., Kühne, B., Gellynck, X., Guerrero, L., Hersleth, M., \& Verbeke, W. (2013). Innovations in traditional foods: Impact on perceived traditional character and consumer acceptance. Food Research International. https://doi.org/10.1016/j.foodres.2013.10.027.

Vecchio, R., \& Annunziata, A. (2012). Italian consumer awareness of layer hens' welfare standards: A cluster analysis. International Journal of Consumer Studies. https://doi.org/10.111 1/j.1470-6431.2011.01040.x.

Vega-Zamora, M., Torres-Ruiz, F. J., \& Parras-Rosa, M. (2018). Towards sustainable consumption: Keys to communication for improving trust in organic foods. Journal of Cleaner Production. https://doi. org/10.1016/j.jclepro.2018.12.129.

Verbeke, W. (2009). Stakeholder, citizen and consumer interests in farm animal welfare. Animal Welfare, $18,325-333$.

Vermeir, I., \& Verbeke, W. (2006). Sustainable food consumption: Exploring the consumer "'attitude-behavioral intention" gap. Journal of Agricultural and Environmental Ethics. https://doi. org/10.1007/s10806-005-5485-3.

Yeates, J. W. (2010). Death is a welfare issue. Journal of Agricultural and Environmental Ethics. https:// doi.org/10.1007/s10806-009-9199-9.

Zander, K., \& Hamm, U. (2010). Consumer preferences for additional ethical attributes of organic food. Food Quality Preferences. https://doi.org/10.1016/j.foodqual.2010.01.006.

Zander, K., Stolz, H., \& Hamm, U. (2013). Promising ethical arguments for product differentiation in the organic food sector. A mixed methods research approach. Appetite. https://doi.org/10.1016/j.appet .2012.11.015.

Publisher's Note Springer Nature remains neutral with regard to jurisdictional claims in published maps and institutional affiliations. 